\title{
Keberhasilan Format Program Drama Dalam Menjaring Penonton Televisi (Studi Kasus Sinetron Ojek Pengkolan RCTI)
}

\author{
A.Munanjar S.I.Kom, M.M ${ }^{1}$, Nina Kusumawati S.I.Kom, M.Si ${ }^{2}$ \\ ${ }^{1}$ Universitas Bina Sarana Informatika, azwar.azw@bsi.ac.id \\ ${ }^{2}$ Universitas Bina Sarana Informatika, nina.nki@bsi.ac.id
}

\begin{abstract}
ABSTRAK
Persaingan stasiun televisi dalam menjaring penonton dilakukan dengan produksi program semenarik mungkin. Siaran program dikatakan berhasil jika mampu menempatan share dan rating tertinggi. Program yang masih menduduki share dan rating tertinggi hingga saat ini adalah format program drama. Salah satu format drama adalah tayangan sinetron. Penelitian ini menggunakan metode kualitatif dengan pendekatan studi kasus. Data yang digunakan adalah tayangan sinetron Tukang Ojek Pengkolan yang tayang di stasiun RCTI. Temuan dari penelitian ini adalah format program menjadi kekuatan dalam produksi program siaran dan format program drama adalah format yang paling mampu menjaring penonton televisi.
\end{abstract}

Kata kunci: format program, drama televisi

\section{ABSTRACT}

Television station competition in attracting viewers is done with the production of programs as attractive as possible. Broadcast programs are said to be successful if they are able to place the highest share and rating. The program that still occupies the highest share and rating to date is the drama program format. One of the drama formats is soap opera shows. This research uses a qualitative method with a case study approach. The data used is the soap opera show of taxi drivers who aired on RCTI station. The findings of this study are that the format of the program is a strength in the production of broadcast programs and the format of the drama program is the format most able to capture television viewers.

\section{Keywords: program format, television drama}

\section{Pendahuluan}

Persaingan stasiun televisi dalam merebut hati penonton dapat dilihat dari ragam tayangan program siarannya. Setiap format program siaran ditempatkan pada slot penayangannya tersendiri dan memiliki kompetitor sendiri-sendiri. Persaingan tayangan program ini memunculkan program siaran mana yang memiliki share dan rating yang tinggi. Program siaran yang mampu menempatkan diri pada share dan rating teratas ini dapat dikatakan sebagai program unggulan dari stasiun televisi itu sendiri.
Keberhasilan program televisi masih berpegang pada rating dan share. Hal ini menuntut para pembuat program berusaha keras untuk menjaring penonton sebanyak-banyaknya dengan berpijak pada format program siaran. Dalam waktu siaran dua puluh empat jam, stasiun televisi berusaha memenuhi kebutuhan penontonnya untuk mendapatkan siaran informasi dan hiburan. Beragam format pun secara bergantian disiarkan mulai dari siaran berita, infotainment, magazine show, drama, talkshow, dokumenter tv atau program kuis yang disajikan dan dikemas semenarik mungkin 
berdasarkan target penontonnya masingmasing. Namun, format program drama dinilai masih menjadi format yang dapat menjaring penonton paling banyak di antara format siaran lainnya. Hal ini dapat dilihat dari share dan rating yang menunjukan program drama masih menduduki peringkat teratas dari format program lainnya.

Program drama dalam jajaran program siaran televisi dapat dilihat dari tayangan sinetron (sinema elektronik), drama series, film televisi (FTV) dan situasi komedi (sitkom). Di antara format program drama televisi ini sendiri, sinetron lebih diunggulkan dalam menjaring penonton sehingga menempati slot siaran prime time. Karena keberhasilan sinetron inilah stasiun televisi bahkan memiliki lebih dari satu produksi sinetron. Stasiun televisi RCTI, SCTV, dan ANTV bersaing dalam program sinetron. Ketiga stasiun televisi ini memulai penayangan sinetron dari pukul 18:00 - 23:00 WIB dengan durasi siaran sinetron berkisar antara satu hingga dua jam. Satu di antara sinetron yang tayang pada jam tersebut adalah sinetron Tukang Ojek Pengkolan.

Sinetron Tukang Ojek Pengkolan menceritakan kehidupan di balik gedung bertingkat Ibu kota. Rojak dan Tati adalah pasangan muda yang kehidupannya mereka ditompang oleh Rojak yang bekerja sebagai ojek pengkolan. Tak hanya Rojak, Purnomo dan Sutisna juga memiliki pekerjaan sebagai tukang ojek pengkolan. Masalah kehidupan masing-masing dari mereka menjadi bumbu dalam cerita ini. Rojak (Ojak) dituntut mertuanya untuk dapat memiliki pekerjaan yang lebih baik dan mumpuni dari tukang ojek karena memiliki ijazah D3. Kisah cinta Purnomo (Pur) yang penuh lika-liku bisa membuat penonton turut patah hati, terlebih ketika ia ditinggal menikah oleh Novita. Sedangkan Sutisna (Tisna). Sedangkan Sutisna (Tisna) memiliki karakter polos dan sopan yang menjadi daya tariknya dalam sinetron ini. Kekuatan sinetron ini sendiri adalah latar ceritanya yang dekat dengan masyarakat dan dibalut dengan nuansa komedi.

Melihat hal ini penulis tertarik untuk menganalisis lebih lanjut bagaimana program sinetron dapat menduduki posisi teratas dalam share dan rating program televisi dengan studi kasus tayangan sinetron Tukang Ojek Pengkolan yang tayang di stasiun televisi RCTI.

\section{KAJIAN LITERATUR}

\section{Program Siaran Televisi}

Siaran televisi sesuai dengan sifatnya yang dapat diikuti secara audio dan visual (suara dan gambar) secara bersamaan oleh semua lapisan masyarakat, makan televisi tidak dapat memuaskan semua lapisan masyarakat. Siaran televisi dapat membuat kagum dan memukau sebagian penontonnya, tetapi sebaliknya siaran televisi dapat membuat jengkel dan rasa tidak puas bagi penonton lainnya (Morissan, 2008).

Dari pernyataan tersebut dapat dipahami bahwa setiap tayangan program siaran televisi ditujukan pada segmentasi penonton tersendiri. Berdasarkan segmentasi demografi, secara usia, anakanak memiliki tontonan program siaran anak seperti tayangan film animasi (kartun). Morissan, 2008 mengatakan "program untuk anak-anak yang paling populer adalah program animasi yang biasanya menjadi andalan televisi untuk meraih perhatian anak-anak". Begitu pula dengan usia remaja, dewasa, dan orang tua yang memiliki tontonan program siaran yang khususkan pada segmentasi mereka. Hal ini pula yang mendasari hadirnya format program televisi.

Menurut (Latief, Rusman. Utud, 2015) "Secara umum program siaran televisi terbagi menjadi dua bagian, yaitu program hiburan populer disebut program entertaiment dan informasi disebut program berita (news)". Selanjutnya Latief dan Utud membuat 
perbedaan dan karakteristik perbedaan antara program hiburan dan informasi yang dapat dilihat pada tabel berikut :

Tabel 1

Perbedaan dan Karakteristik Program Hiburan dan Informasi

\begin{tabular}{|l|l|}
\hline \multicolumn{1}{|c|}{ Hiburan } & \multicolumn{1}{c|}{ Informasi } \\
\hline Imajinatif & Faktual \\
\hline Fiksional & Non-Fiksional \\
\hline Artistik & Efektif \\
\hline Dramatik & $\begin{array}{l}\text { Improvisasi } \\
\text { Terbatas }\end{array}$ \\
\hline $\begin{array}{l}\text { Improvisasi } \\
\text { terbatas }\end{array}$ & Nyata \\
\hline Abstrak & Etika \\
\hline Norma-norma & Waktu Terbatas \\
\hline Waktu tak terbatas & Percaya \\
\hline Senang & \\
\hline
\end{tabular}

Walaupun terdapat perbedaan dan karakteristik dari program hiburan dan informasi, tapi tidak membuat batasan itu menjadi berdiri sendiri, tetapi ada beberapa program yang berdiri di dua jenis karakteristik program tersebut, tergolong sebagai program, informasi dan juga hiburan, seperti program talk show dan program variety show. (Latief, Rusman. Utud, 2015)

Adapun format program drama dapat dikategorikan sebagai program hiburan. (Naratama, 2004) mengatakan program drama merupakan format acara televisi yang diproduksi dan diciptakan melalui proses imajinasi kreatif dari kisah-kisah drama atau fiksi dari setiap pelakunya.

\section{Drama Televisi}

Program drama masih menjadi program hiburan yang tidak pernah terpinggirkan oleh program lainnya walaupun beberapa stasiun televisi swasta berfokus pada program informasi, namun program drama tetap saja menjadi program yang disukai penonton dan masih menempati posisi pertama disusul reality show, komedi, musik dan program informasi (Latief, Rusman. Utud, 2015).

Hal tersebut dapat dilihat dari sebaran daily televisi program televisi yang memperlihatkan dominasi program drama menempati posisi teratas di antara program lainnya. Adapun gambaran tesebut dapat dilihat pada gambar di bawah ini.

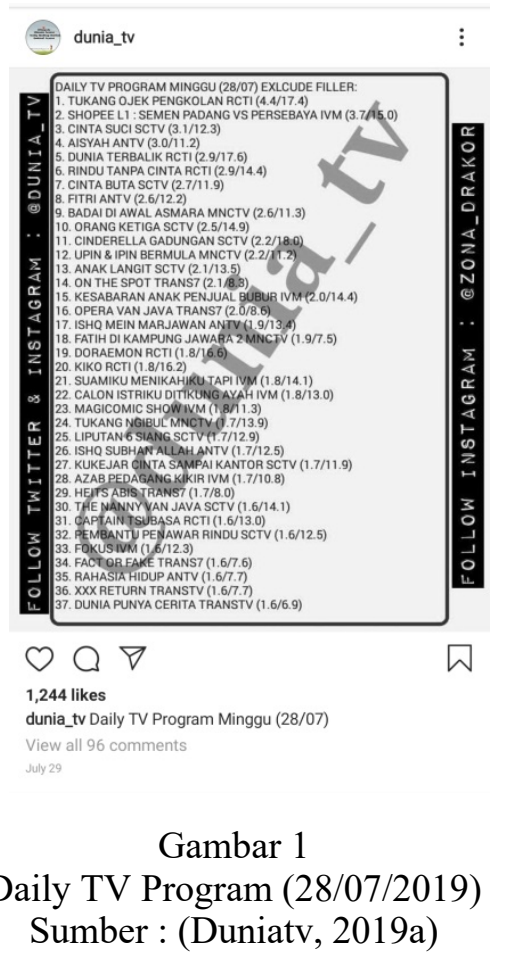

Dari daily TV program pada 28 Juli 2017 dapat dilihat posisi teratas ditempati program drama tv, sinetron Tukang Ojek Pengkolan RCTI (Share 3.1/Rating 12.3) disusul sinetron lainnya Cinta Suci SCTV (Share 3.1/Rating 17.4), Aisyah ANTV (Share 3.0/Rating 11.2), Dunia Terbalik RCTI (Share 2.9/Rating 17.6) dan Rindu Tanpa Cinta (Share 2.9/Rating 14.4).

Daya tarik sinetron masih menjadi program unggulan sehingga dapat menjaring penonton televisi maka tak dapat dipungkiri stasiun televisi berusaha menghadirkan sinetron dengan cerita-cerita yang mampu membuat penonton betah menyaksikannya. 
Adapun menurut (Latief, Rusman. Utud, 2015) Program drama populer disebut sinetron (sinema elektronik) adalah program televisi yang menyajikan cerita mengenai kehidupan atau karakter seseorang atau beberapa orang yang diperankan oleh aktor/aktris yang terlibat dalam konflik.

Pemilihan aktor/aktris dalam memerankan cerita pada sinetron pun menjadi nilai jual dan menjadi daya tarik dari sinetron itu sendiri, tapi unsur jalannya cerita yang dekat dengan kehidupan masyarakatlah lebih diutamakan karena dapat membangkitkan emosi penonton.

\section{Kekuatan Format Program dalam Menjaring Penonton}

Dalam mendapatkan jumlah penonton, stasiun televisi akan menempatkan program terbaiknya pada waktu prime time. Menurut (Latief, Rusman. Utud, 2015) program yang selalu mendapatkan penonton banyak ditempatkan jam tayang prime time pukul 19.00-21.00. Hingga saat ini, prime time masih diduduki oleh format program drama, yakni sinetron. Stasiun televisi RCTI, SCTV dan ANTV menempatkan sinetron terbaiknya pada jam tersebut. Berikut adalah jadwal siaran pada Senin 05 Agustus 2019 :
Adapun jadwal siaran sinetron stasiun RCTI, Rindu Tanpa Cinta (Tayang 18.00 WIB), Tukang Ojek Pengkolan (Tayang 19.00 WIB) dan Dunia Terbalik (Tayang 21.15 WIB). Sedangkan jadwal siaran sinetron stasiun SCTV, Cinta Anak Muda (Tayang 18.00 WIB), Cinta Karena Cinta (Tayang 20.00 WIB), dan Orang Ketiga (Tayang 22.00 WIB). Serta jadwal siaran sinetron stasiun ANTV, Fitri ( Tayang 17.45 WIB), Aisyah (Tayang 19.30 WIB), dan Rahasia Hidup (Tayang 21.15 WIB).

Menurut (Latief, Rusman. Utud, 2015) kekuatan format adalah program yang menonjolkan kelebihan dan kemasan, rancangan, atau konsepnya yang berhubungan dengan cara penyajiannya. Adapun format hiburan dengan pendekatan artistik misalnya, sinetron kekuatannya ada pada cerita atau pemainnya (Latief, Rusman. Utud, 2015). Dan berikut jejeran program sinetron yang mendapatkan jumlah penonton terbanyak dalam persaingannya, RCTI, SCTV dan ANTV pada daily TV Program pada senin 5 Agustus 2019.


Gambar 2

Jadwal Acara Stasiun TV

Sumber : (Duniatv, 2019b) 


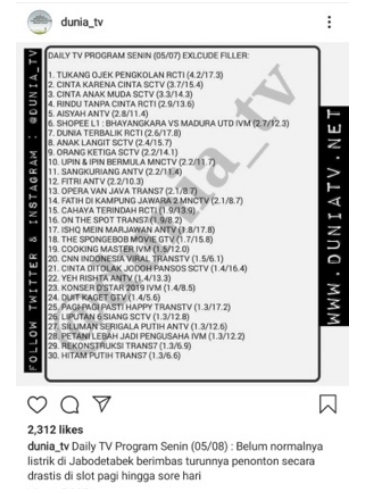

Gambar 3

Daily TV Program (05/08/2019)

Sumber : (Duniatv, 2019a)

Di antara program unggulan masingmasing stasiun televisi, sinetron Tukang Ojek Pengkolan menempatkan diri pada posisi pertama dengan rating 17.3 dan share 4.2. Di posisi kedua sinetron Cinta Karena Cinta SCTV dengan rating 15.5 dan share 3.7. Sedangkan sinetron ANTV sendiri, Aisyah menempati posisi lima dengan rating 11.4 dan share 2.9.

\section{METODE PENELITIAN}

Metode penelitian kualitatif sering disebut metode penelitian naturalistik karena penelitiannya dilakukan pada kondisi yang alamiah (natural setting); disebut juga metode etnographi, karena pada awalnya metode ini lebih banyak digunakan untuk penelitian antropologi budaya; disebut metode kualitatif, karena data yang terkumpul dan analisanya lebih bersifat kualitatif (Sugiyono, 2012).

Studi kasus merupakan strategi atau pendekatan pada metode kualitatif. Stake dalam (Creswell, 2010) mengatakan bahwa studi kasus merupakan strategi penelitian di mana di dalamnya peneliti menyelidiki secara cermat suatu program, peristiwa, aktivitas, proses atau sekelompok indivisu. Kasus-kasus dibatasi oleh waktu dan aktivitas, dan peneliti mengumpulkan informasi secara lengkap dengan menggunakan berbagai prosedur pengumpulan data berdasarkan waktu yang telah ditetapkan.
Metode penelitian ini menggunakan metode kualitatif dengan pendekatan studi kasus sinetron Tukang Ojek Pengkolan RCTI. Data diperoleh melalui data primer dan data sekunder. Data primer yang digunakan yaitu tayangan program sinetron Tukang Ojek Pengkolan RCTI yang tayang setiap hari pada pukul 19.00-21.00 WIB dan melalui tayangan youtube Tukang Ojek Pengkolan yang ada di channel youtube RCTI - Layar Drama Indonesia Episode 1904-1905 (05/08/2019) Sedangkan untuk data sekundernya menggunakan referensi terkait yang berasal dari buku, artikel online, serta jurnal hasil penelitian lain yang berkaitan dengan penelitian ini.

\section{PEMBAHASAN}

Dalam pembahasan keberhasilan format program dianalisa berdasarkan studi kasus sinetron Tukang Ojek Pengkolan RCTI dengan elemen keberhasilan program televisi menurut Morissan dalam buku Manajemen Media Penyiaran. Ada pun (Morissan, 2008) merangkum keberhasilan sebuah program kedalam tujuh elemen, yaitu:
1. Konflik
2. Durasi
3. Kesukaan
4. Konsistensi
5. Energi
6. Timing
7. Tren

a. Konflik

Konflik merupakan benturan kepentingan atau benturan karakter di antara tokoh-tokoh yang terlibat. Tanpa adanya konflik, maka kecil kemungkinan program itu akan mampu menahan perhatian audien (Morissan, 2008) Dalam sinetron Tukang Ojek Pengkolan Sendiri konflik dibangun lewat keseharian hidup para tokoh-tokohnya. Pada episode 1904-1905 konflik yang dibangun fokus pada cerita percintaan Mas Pur, di mana mas Pur dihadapkan pada dua pilihan wanita, Mas Pur sedang dalam 
perencanaan menikah dengan Jeni tetapi Lola mengatakan kejujuran hatinya pada Mas Pur. Konflik percintaan Mas Pur sendiri dalam sinetron menjadi hal yang dinanti oleh para penonton. Dimana sebelumnya penonton turut patah hati dengan kegagalan percintaan Mas Pur dengan Novita.

b. Durasi

(Morissan, 2008) Mengatakan suatu program yang berhasil adalah program yang dapat bertahan selama mungkin. Morissan juga menambahkan kata kunci untuk mempertahankan selama mungkin suatu program adalah dengan tidak kekurangan ide dan hal yang sering membantu memperpanjang cerita adalah memberi kesempatan kepada tokoh dan karakter untuk muncul dalam cerita. Tukang Ojek Pengkolan sendiri tayang perdana pada 25 April 2015 dengan jam siaran awal pukul 17.00-18.45 WIB (Durasi 105 menit) dan sekarang berganti waktu tayang 19.00-21.15 WIB (135 menit) yang menempati slot prime time. Pada tanggal 05 Agustus 2019 sudah mencapai 1904-1905 episode pada empat tahun penayangannya.

c. Kesukaan

(Morissan, 2008) menyebutkan bahwa sebagian audien memilih program yang menampilkan pemain utama atau pembawa acara yang mereka sukai, yaitu orang-orang yang membuat audien merasa nyaman. Dilihat dari pemain yang mengisi sinetron Tukang Ojek Pengkolan, tidak menyuguhkan aktris/aktor yang termasuk artis kelas atas. Namun malah sebaliknya, banyak wajah-wajah baru yang menjadi mengisi layar televisi. Bahkan pemeran beberapa tokoh sendiri merupakan warga sekitar atau orang-orang yang terlibat dalam produksi Tukang Ojek Pengkolan itu sendiri. Ada pun cast dari Tukang Ojek
Pengkolan di anatranya sebagai berikut :

1. Eza Yayang Sebagai Ojak

2. Purry Setya sebagai Purnomo/Mas Pur

3. Andre Sulistriandri sebagai Sutisna/Tisna

4. Fitrie Rahmadhina sebagai Tati (Istri pertama Ojak)

5. Tika Bravani sebagai Mbak Deno (Istri Ojak kini)

6. Ranty Purnamasari sebagai Emak/Emak Tati

7. dll

\section{d. Konsistensi}

Suatu program harus konsisten terhadap tema dan karekter yang dibangun sejak awal. Dengan demikian tidak boleh ada terjadi pembelokan atau penyimpangan tema atau karakter di tengah jalan yang akan membuat audien bingung dan akhirnya meninggalkan program itu (Morissan, 2008) Dilihat dari tema, sinetron Tukang Ojek Pengkolan mengangkat tema kehidupan sosial masyarakat bawah dengan mengambil setting latar mayarakat yang hidup ditengah megahnya gedung-gedung bertingkat ibu kota. Tema juga mengalir mengikuti keseharian hidup sebagai tukang ojek. Masalah-masalah yang diangkat juga merupakan masalah keseharian yang dekat dengan penonton, seperti jalinan hubungan dengan mantan mertua, suami yang takut istri karena istrinya galak, problematika gagalnya urusan percintaan, dan masalah-masalah lainnya.

e. Energi

Suatu program harus memiliki cerita yang tidak boleh lamban apalagi monoton. Audien tidak boleh dibiarkan bingung atau mereka masih tidak tahu arah cerita suatu drama padahal waktu tayang sudah 25\% terlewati (Morissan, 2008). Pada sinetron Tukang Ojek Pengkolan sendiri memiliki sub dalam alur cerita dari masing- 
masing persoalan dan masalah kehidupan yang dihadapi oleh ketiga tokoh utama, Ojak, Mas Pur dan Tisna. Ketiga tokoh ini membawa cerita masing-masing tapi masih dalam satu benang merah, sehingga dengan durasi tayang 135 menit penonton masih dibawa larut oleh jalinan cerita ditiap episodenya.

f. Timing

Menurut (Morissan, 2008) Programmer dalam memilih suatu program siaran harus mempertimbangkan waktu penayangan (timing), yaitu apakah program bersangkutan itu sudah cocok atau sesuai dengan zamannya. Tayang perdana tahun 2015, Tukang Ojek Pengkolan bersaing dengan Sitkom OK JEK NET TV. Di tengah ramainya ojek online dan tayangan OK JEK yang menyuguhkan cerita kehidupan driver ojek online, sinetron Tukang Ojek Pengkolan mengambil latar cerita sebaliknya, menceritakan kehidupan para ojek pangkalan. Dengan kemasan produksi yang dekat dengan masyarakat dan membuat alur cerita yang juga mengikuti apa yang terjadi pada masyarakat saat ini membuat sinetron ini mampu bertahan hingga saat ini (2019) dan mampu menduduki peringkat tertatas dalam menjaring penonton televisi.

g. Tren

Tren bukanlah suatu hal yang terlalu penting untuk diikuti, namun tren dapat menjadi jalan yang akan menunjukkan apa yang tengah disukai masyarakat. Kesadaran terhadap tren yang sudah berlalu dapat membantu programmer menghindari atau menolak program dengan konsep yang sudah usang (Morissan, 2008) Tanpa mengikuti tren dari sinetron-sinetron yang menjadi kompetitor yang dalam produksinya mengedapankan aktor/aktris terkenal, sinetron Tukang Ojek Pengkolan lebih menggunggulkan uncur cerita yang dekat dengan masyarakat. Unsur cerita yang lebih dekat dengan penonton dapat menjadi daya tarik tersendiri karena dirasa lebih natural sekali pun cerita tersebut adalah ceita fiksi. Hal ini dapat dilihat juga dari sinetron Si Doel yang hingga kini masih menjadi tayangan sinetron favorit penonton. Sinetron Tukang Ojek Pengkolan dinilai sudah memiliki ikatan dengan penontonnya melalui kesederhanaan jalannya cerita yang disajikan. Dan keberhasilan sinetron ini sendiri adalah dapat menjaring penonton televisi dengan menempati share dan rating teratas dalam setiap pekan.

\section{PENUTUP}

Dalam menentukan program siaran televisi sangat diperlukan pemahaman tentang format program siaran. Kekuatan setiap format program sendiri menentukan segmen penonton. Setiap program yang ditayangkan akan berusaha menjaring sebanyak mungkin penontonnya. Secara format program, drama televisi sendiri masih menempatkan diri sebagai format program terkuat dalam menjaring penonton. Hingga saat ini, berdasarkan data dialy TV program format program drama mandapati share dan rating tertinggi di antara format program siaran lainnya.

Dalam penelitian ini tak luput dari kekurangan, keterbatasan waktu menjadi salah satu faktornya. Saran kepada peneliti yang tertarik dalam meneliti di bidang yang terkait adalah agar dapat menambahkan uraian tentang segmentasi penonton, khususnya penonton sinetron.

\section{REFERENSI :}

Creswell, J. W. (2010). RESEARCH DESIGN Pendekatan Kualitatif, Kuantitatif, dan Mixed (3rd ed.; S. Z. Qudsi, ed.). Yogyakarta: Pustaka Pelajar. 
Duniatv. (2019a). Dunia_tv. Retrieved August 8, 2019, from https://www.instagram.com/dunia tv/

Duniatv. (2019b). Jadwal TV. Retrieved August 5, 2019, from https://www.jadwaltv.net/

Latief, Rusman. Utud, Y. (2015). SIARAN TELEVISI NONDRAMA Kreatif, Produktif, Public Relation, dan Iklan (2nd ed.). Jakarta:

Kencana.

Morissan. (2008). MANAJEMEN MEDIA PENYIARAN Strategi Mengelola Radio \& Televisi (1st ed.). Jakarta: Kencana.

Naratama. (2004). Menjadi Sutradara Televisi, dengan Single dan Multicamera. Jakarta: Grasindo.

Sugiyono. (2012). Metode Penelitian Kuantitatif, Kualitatif dan $R \& D$ (17th ed.). Bandung: Alfabeta.

\section{BIODATA PENULIS}

A.Munanjar S.I.Kom, MM karyawan staf akademik program studi penyiaran Fakultas Bahasa dan Komunikasi Univeristas Bina Sarana Informatika Jakara.

Nina Kusumawati S.PT, M.Si staf pengajar Universitas Bina Sarana Informatika Fakultas Komunikasi dan Bahasa. Pendidikan D4 Produksi Acara TV STTM MMTC. S2 STIKOM Interstudi jurusan Entertaiment Communication. 